\title{
Superbugs causing infections at a tertiary care hospital and the return of pre-antibiotic era!
}

\author{
Kalyan Rajkumar', Shruti Radera², Jyotsna Agarwal'3, Mastan Singh ${ }^{3}$ \\ ${ }^{1}$ Associate Professor, Department of Microbiology, King George's Medical University, Lucknow, Uttar Pradesh, India, ${ }^{2}$ MD PhD Scholar, \\ Department of Microbiology, King George's Medical University, Lucknow, Uttar Pradesh, India, ${ }^{3}$ Professor, Department of Microbiology, \\ King George's Medical University, Lucknow, Uttar Pradesh, India
}

Aims and Objectives: Increase in the incidence of Escherichia coli and Klebsiella pneumoniae carrying New Delhi metallo beta lactamase-1 (NDM-1) gene are called superbugs is of great concern as presence of bla $\mathrm{NDM}_{1}$ gene makes E.coli and K.pneumoniae highly resistant to most of currently available antibiotics. This study was planned to observe the burden of bla $_{\mathrm{NDM}-1}$ gene carrying E. coli and K.pneumoniae at a tertiary care hospital in northern India. Materials and Methods: A total of 1709 E. coli and $327 \mathrm{~K}$. pneumonia nonrepitive isolates were taken from various clinical samples received in a tertiary care hospital in northern India Lucknow during the period from May 2012 to April 2013. Carbapenemase production was phenotypically detected in all the carbapenem resistant isolates by modified Hodge test. Metallo- $\beta$-lactamase production was detected by using meropenem and imipenem discs with and without EDTA and $b / a_{\mathrm{NDM}-1}$ gene was detected by polymerase chain reaction. Results: Over all metallo $\beta$ - lactamase production was found in $82 \%$ and $88.89 \%$ of carbapenem resistant E.coli and K. pneumonia respectively. Out of 366 carbapenem resistant isolates, 102 were found positive for bla $a_{\text {NDM-1 }}$ gene out of which 89 were E.coli and 13 were K. pneumoniae. Conclusions: With limited treatment options left for this crisis situation like the pre-antibiotic era; it is an alarm for rational antibiotic therapy usage and intensive education programs.

Key words: New Delhi metallo beta lactamase-1, Escherichia coli.Klebsiella pneumoniae. Metallo- $\beta$-lactamase

\section{INTRODUCTION}

During the last two decades, appearance of $\beta$-lactam resistance specially to $3^{\text {rd }}$ and $4^{\text {th }}$ generation cephalosporin in members of enterobacteriaceae family arose as a serious problem to global health. ${ }^{1}$ Currently carbapenem are the therapeutic drug of choice for treating serious infections caused by Escherichia coli and Klebsiella pneumoniae. ${ }^{2}$ One of the common mechanism of carbapenem resistance in E.coli and $K$. pneumoniae is production of carbapenemase enzyme. Recently a novel $\beta$-lactamase NDM-1 has been reported in multidrug resistant E.coli and K.pneumoniae. NDM-1 gene in Enterobacteriaceae isolates were reported from patients in India, Pakistan, Bangladesh and the UK in 2008-2009. ${ }^{3}$ NDM-1 gene is being reported worldwide, however exact burden of NDM-1 gene in world is not known as very few studies has been done on NDM-1 gene and epidemiological data has not been known so far.

It is necessary to detect these strains as soon as possible and suitable infection control interventions should be implemented for all patients infected or colonized with MBL producing bacteria.

\section{MATERIAL AND METHODS}

\section{Study isolates}

A total of 1709 E.coli and 327 K.pneumoniae isolates were taken from the culture of 20,674 various clinical samples (urine, pus, blood, cerebrospinal fluid, endotracheal aspirate, catheter tips etc) received in the bacteriology laboratory of the Microbiology department during one year period from 
May 2012 to April 2013. All the carbapenem resistant isolates included in the study were further identified by following accepted laboratory criteria. ${ }^{4}$

\section{Antimicrobial susceptibility testing}

Antimicrobial susceptibility against isolated E.coli and K.pneumoniae for various antimicrobial agents using beta-lactam and non-beta lactam antibiotic discs were determined by Kirby-Bauer disc diffusion method and results were interpreted as per Clinical and Laboratory Standards Institute (CLSI) guidelines. ${ }^{5}$ Antibiotic discs were procured from Hi-Media, Mumbai, India, except imipenem, which was from BD Diagnostics, Franklin Lakes, NJ, USA. EUCAST guideline 2012 suggest MIC method for colistin drug susceptibility. ${ }^{6}$ Reference grade powder for imipenem and meropenem were obtained from Lac Zene Biosciences, Delhi, India. Minimum inhibitory concentration (MIC) values for imipenem, meropenem and colistin were determined by agar dilution method. Results were interpreted as standard protocol. All the isolates with reduced susceptibility to meropenem and/or imipenem on disc diffusion testing and/or MIC were screened for carbapenemase production. Phenotypic detection for carbapenemase production was done by modified hodge test. ${ }^{5}$ K.pneumoniae ATCC BAA-1705 as positive control and $K$. pneumoniae ATCC BAA-1706 as negative controls were used for MHT.

MBL productionwas detected in isolates with reduced susceptibility to imipenem and/or meropenem using combined disc diffusion test by imipenem $(10 \mu \mathrm{g})$ and $0.1 \mathrm{M}$ ethylenediaminetetraacetic acid (EDTA: $292 \mu \mathrm{g}$ ) as described previously by Franklin et al. ${ }^{7}$ This was complemented by the Modified Hodge test and the double disc synergy test with imipenem $(10 \mu \mathrm{g})$ alone and imipenem $(10 \mu \mathrm{g})+\mathrm{EDTA}(750 \mu \mathrm{g})$ for all the isolates resistant to any carbapenem as performed earlier by Lee et al. ${ }^{8}$

Molecular detection of $b / a_{\text {NDM-1 }}$ gene-

Template DNA from meropenem and/or imipenem resistant strain was prepared from freshly cultured by re-suspending 3-5 colonies in $100 \mu \mathrm{L}$ of molecular grade water, and then by heating at $95^{\circ} \mathrm{C}$ for 10 minutes. The bacterial lysate was centrifuged at 10,000 rpm for $2 \mathrm{~min}$, the supernatant was transferred to new eppendorf tube and used as DNA template for PCR amplification. K.pneumoniae ATCC BAA-2146 procured from Eurofins Genomics, MWG Biotech AG primer microbiologics KWIK STIC was used as positive control for NDM-1 gene. The resistance gene was amplified by polymerase chain reaction (PCR) by using previously published primers NDM-Fm 5'GGTTTGGCGATCTGGTTTTC-3'and NDM-Rm-5'-CGGAATGGCTCATCACGATC-3. ${ }^{9-11}$ specific for $b l a_{\mathrm{NDM}-1}$ in selected meropenem and/or imipenem resistant strains. ${ }^{12}$ The Amplified product was analysed on $2 \%(\mathrm{w} / \mathrm{v})$ agarose gel containing $(0.5 \mu \mathrm{l} / \mathrm{ml})$ of ethidium bromide along with molecular weight marker (100 bp) electrophoretically. Constant current (80V) was maintained for $2 \mathrm{hr}$ and analysed by $264 \mathrm{~nm}$ wavelength UV transilluminator and gel doc (alphalmager3400HP) was used for documentation. A sharp band $621 \mathrm{bp}$ of amplified DNA visualized, considered to be positive (Figure 1).

\section{RESULTS}

Out of 1709 E.coli and 327 K. pneumoniae isolates, 330 E.coli and 36 K.pneumoniae isolates were resistant to carbapenem. The patients suffering from these carbapenem resistant isolates having various risk factors [Table 1]. Percentage of blaNDM-1 positive isolates among carbapenem resistant E.coli and K.pneumoniae were 26.97\%(89/330) \& $36.11 \%(13 / 36)$ respectively. Majority of patients having infection with bla $a_{\text {NDM-1 }}$ gene containing isolates were in 15-60 years of age group. Majority of the bla $\mathrm{NDM}_{-1}$ gene positive isolates were obtained from ICU and wards. All $b_{\text {NDM-1 }}$ producing E. coli and K. pneumonia were susceptible to colistin on MIC however only $53.9 \%$ E.coli and $61.5 \%$ K. pneumoniae were susceptible to tigecycline. For other antimicrobials, $b l a_{\text {NDM- }}$ positive isolates showed variable susceptibility pattern [Table 2]. Out of total $89 \mathrm{bla}_{\mathrm{NDM}-1}$ positive E.coli, only 1 isolate was found moderately sensitive to meropenem on MIC, however it was resistant to imipenem. All isolates of K. pneumoniae with bla ${ }_{\text {NDM-1 }}$ positive were resistant to both meropenem and imipenem by MIC method. Range of MIC value for meropenem, imipenem and colistin were $2-16 \mu \mathrm{g} / \mathrm{ml}, 4-16 \mu \mathrm{g} / \mathrm{ml}$ and $0.5-1 \mu \mathrm{g} / \mathrm{ml}$ respectively for E.coli and $4-16 \mu \mathrm{g} / \mathrm{ml}, 4-8 \mu \mathrm{g} / \mathrm{ml}$ and $0.5-1 \mu \mathrm{g} / \mathrm{ml}$ respectively for K.pneumoniae.

\section{DISCUSSION}

Enterobacteriaceae members are common causes of both health care and community acquired infections, raising the possibility of spread of resistant organisms

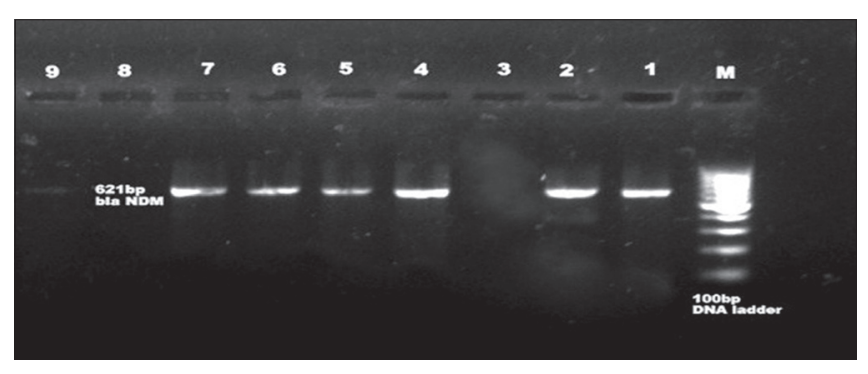

Figure 1: Representative gel picture showing amplification of $b / a_{\mathrm{NDM}-1}$ gene (621bp). Lane M: 100 bp DNA ladder; Lanes 1 and 2: Positive control Klebsiella pneumoniae ATCC BAA-2146; Lane 3: Negative control; Lane 4-9: Clinical isolates 


\begin{tabular}{|c|c|c|c|c|}
\hline \multirow[t]{2}{*}{ Risk factors } & \multicolumn{2}{|c|}{ CREC* $(n=330)$} & \multicolumn{2}{|c|}{$\mathrm{CRPK}^{* *}(n=36)$} \\
\hline & Number of patients & Percentage & Number of patients & Percentage \\
\hline ICU stay $>48$ hrs & 61 & 18.49 & 5 & 13.89 \\
\hline Duration of hospital stay $>3$ days & 190 & 57.58 & 24 & 66.67 \\
\hline \multicolumn{5}{|c|}{ Exposure to antimicrobials within last 14 days } \\
\hline $\mathrm{BL}+$ & 197 & 59.70 & 19 & 52.78 \\
\hline AG++ & 206 & 62.42 & 24 & 66.67 \\
\hline $\mathrm{FQ+++}$ & 162 & 49.1 & 8 & 22.22 \\
\hline AA++++ & 104 & 31.52 & 4 & 11.11 \\
\hline Presence of devices & 192 & 58.18 & 23 & 63.89 \\
\hline • Shunt & 33 & 10 & 6 & 16.67 \\
\hline - Prosthesis & 6 & 1.82 & 4 & 11.11 \\
\hline - I V catheter & 39 & 11.82 & 3 & 8.33 \\
\hline - ICD tube & 15 & 4.55 & 0 & 0 \\
\hline • ET tube & 46 & 13.94 & 4 & 11.11 \\
\hline - Tracheal tube & 14 & 4.24 & 1 & 2.78 \\
\hline - Urinary catheter & 53 & 16.06 & 7 & 19.44 \\
\hline - Drain & 6 & 1.82 & 1 & 2.78 \\
\hline - Stent & 10 & 3.03 & 0 & 0 \\
\hline
\end{tabular}

+Betalactams, ++Aminoglycosides, +++Fluoroquinolones, ++++All antibiotics, *Carbapenem resistant $E$. coli, ** Carbapenem resistant $K$. peumoniae, $"$ Intercostal drainage tube, \#\#Endotracheal tube

\begin{tabular}{lcc}
\multicolumn{3}{l}{ Table 2: Antibiotic resistant pattern of NDM-1 } \\
Escherichia coli and & Klebsiella pneumoniae \\
\hline Antibiotics & $\begin{array}{c}\text { Escherichia coli } \\
(\mathbf{n = 8 9 )}\end{array}$ & $\begin{array}{c}\text { Klebsiella } \\
\text { pneumoniae (n=13) }\end{array}$ \\
\hline Piperacillin/tazobactum & $87(97.75)$ & $10(76.9)$ \\
Ceftriaxone & $89(100)$ & $12(92.3)$ \\
Ceftazidime & $89(100)$ & $12(92.3)$ \\
Amikacin & $72(80.1)$ & $11(84.6)$ \\
Ciprofloxacin & $81(91)$ & $11(84.6)$ \\
Aztreonam & $76(85.4)$ & $11(84.6)$ \\
Meropenem & $89(100)$ & $13(100)$ \\
Imipenem & $85(95.5)$ & $12(92.3)$ \\
Ertapenem & $89(100)$ & $12(92.3)$ \\
Tigecycline & $41(46.1)$ & $5(38.5)$ \\
\hline
\end{tabular}

into the community. ${ }^{13}$ Our study gives an initial account on the presence of $b l a_{\text {NDM-1 }}$ gene in a tertiary care hospital in northern India. Amongst all carbapenem resistant study isolates, $b l a_{\mathrm{NDM}-1}$ gene was present in 89 isolates of E. coli $(26.97 \%)$ and 13 K.pneumoniae. In a study done by Kumarasamy et al., in Chennai (India), bla ${ }_{\text {NDM-1 }}$ gene was found in $25.33 \%$ E.coli and $23.33 \%{ }^{9}$ isolates of K.pneumoniae in carbapenem resistant isolates. Over all bla ${ }_{\mathrm{NDM}-1}$ gene was found in 5\% of isolated E.coli and K. pneumoniae, showed almost similar finding with previous study done by Seema et al in which NDM-1 gene was found in $5.39 \%$ of total isolated E.coli and K.pneumoniae. ${ }^{14}$ Out of 102 bla $_{\mathrm{NDM}-1}$ positive isolates $76(74.5 \%)$ were found in hospitalized patients. In our study, only $16(15.68 \%)$ bla NDM-1 $_{1}$ positive isolates were recovered from ICU patients. while in most of previous Indian studies showed that bla $a_{\mathrm{NDM}-1}$ gene positive isolates are found predominantly in ICU patients however some of previous Indian studies have shown greater isolation from non-ICU wards. ${ }^{15,16}$ Eight isolates carrying $b l a_{\mathrm{NDM}-1}$ gene were recovered from patients on ventilator.
All NDM-1-producing isolates of E. coli and K. pneumonia were susceptible to colistin on MIC while in a study done by Kumarasamy et al., colistin showed variable sensitivity pattern to NDM-1 gene isolates. ${ }^{5}$ Reason may be different geographical distribution. Susceptible to tigecycline which are almost consistent with a study done by Seema et al, $2011^{14}$ in which tigecycline susceptibility was present in $46.2 \%$ and Kumarasamy et al., $2010^{3}$ in which it was $64 \%$ and $67 \%$. In our study some of the $b l_{\text {NDM-1 }}$ harbouring isolates were found phenotypically susceptible to one or more carbapenems tested.

So all the carbapenem disc should be used for drug susceptibility with, and if possible molecular analysis should be done in hospital setting because false susceptibility testing may lead to treatment failure.

\section{CONCLUSION}

Present study shows higher rate of resistance to commonly used carbapenems in a tertiary care set up in northern India which may be due to irrational use of antibiotics and responsible genes can transfer from one bacteria to other. It is necessary to detect these strains as soon as possible and suitable infection control interventions should be implemented for all patients infected or colonized with MBL producing bacteria.

\section{REFERENCES}

1. Paterson DL. Resistance in gram-negative bacteria: enterobacteriaceae. Am J Med 2006; 119(6):20-28.

2. P Gisele, Seki LM, Val Passos VL, Pinto MCFG, Guerra LR and 
Asensi MD. Carbapenem-hydrolysing $\beta$-lactamase KPC-2 in Klebsiella pneumoniae isolated in Rio de Janeiro, Brazil. Journal of Antimicrobial Chemotherapy 2009; 63:265-268.

3. Kumarasamy KK, Toleman MA, Walsh TR, Bagaria J, Butt F, Balakrishnan R, et al. Emergence of a new antibiotic resistance mechanism in India, Pakistan, and the UK: a molecular, biological, and epidemiological study. Lancet Infect Dis 2010; 10:597-602.

4. Collee JG, Miles RS and Wan B. Tests for the identification of bacteria. In: Collee JG, Fraser AG, Marmion BP, Simmons A, editors. Mackie and McCartney Practical Medical Microbiology. $14^{\text {th }}$ ed. Edinburgh: Churchill Livingstone; 1996.

5. CLSI. CLSI document M100-S22.Vol. 32. Wayne: Clinical and Laboratory Standards Institute; 2012. Performance Standards for Antimicrobial Susceptibility Testing; Twenty-Third Informational Supplement; pp.44-61.

6. The European Committee on Antimicrobial Susceptibility Testing Breakpoint tables for interpretation of MICs and zone diameters. Version 2.0, 2012:3-7.

7. Franklin $C$, Liolios $L$ and Peleg AY. Phenotypic detection of carbapenem-susceptible metallo- $\beta$-lactamase-producing gramnegative bacilli in the clinical laboratory. J Clin Microbiol 2006; 44(9):3139-3144

8. Lee K, Lim YS, Yong D, Yum JH and Chong Y. Evaluation of the Hodge test and the imipenem-EDTA double-disk synergy test for differentiating metallo-beta lactamase-production isolates of Pseudomonas spp and Acinetobacter spp. J Clin Microbiol 2003;41: 4623-4629.
9. Nordmann P, Poirel L, Carrër A, Toleman MA and Walsh TR. How to detect NDM-1 producers. J Clin Microbiol 2011; 49:718- 721.

10. Ellington MJ, Kistler J, Livermore DM and Woodford N. Multiplex PCR for rapid detection of gene encoding acquired metallo-betalactamase. J Antimicrob Chemother 2007; 59:321-322.

11. Pillai DR, Melano R, Rawte P, Lo S, Tijet N Fuksa M, et al. Klebsiella pneumonia carbapenemase, Canada Emerg Infect Dis 2009; 15:827-829.

12. Poirel L, Dortet L, Bernabeu S and Nordmann P. Genetic features of bla $\mathrm{NDM}_{\mathrm{N}-1}$ positive enterobacteriaceae. Antimicrobial Agents and chemotherapy 2011; 55(11):5403-5407.

13. Bratu S, Brooks S, Burney S, Kochar S, Gupta J, Landman D, et al. Detection and spread of Escherichia coli possessing the plasmid-borne carbapenemase KPC-2 in Brooklyn, New York. Clin Infect Dis 2007; 44:972-975.

14. Seema K, Sen MR, Upadhyay $S$ and Bhattacharjee A. Dissemination of the New Delhi metallo-b-lactamase-1 (NDM-1) among Enterobacteriaceae in a tertiary referral hospital in north India. J Antimicrob Chemother 2011; 66:1646-1647.

15. Deshpande P, Rodrigues C, Shetty A, Kapadia F, Hedge A and Soman R. New Delhi Metallo-beta lactamase (NDM-1) in Enterobacteriaceae: treatment options with carbapenems compromised. J Assoc Physicians India 2010; 58:147-149.

16. Bora A, Ahmed GU, Hazarika NK, Prasad KN, Shukla SK, Randhawa V, et al. Incidence of $b l a_{\text {NDM-1 }}$ gene in Escherichia coli isolates at a tertiary care referral hospital in Northeast India. Indian J Med Microbiol 2013; 31:250-256.

\section{Authors Contribution:}

All the authors were equally involved in drafting and finalizing the manuscript. RK - Concept and design of study, statistically data analysis, supervised research work, manuscript preparation and editing, finalised manuscript; SR - Concept, collected data and literature search, did experimental work, helped in data analysis, helped in manuscript preparation and editing; JA - Concept of study, helped in molecular work, critical revision and editing of manuscript; MS - Concept of study, helped in molecular work, manuscript editing and review.

Reprint Request: Dr. Rajkumar Kalyan, Associate Professor, Department of Microbiology, King George's Medical University, Chowk Lucknow, Uttar Pradesh, Pincode-226003, India. 